\title{
Research on Innovation of News Products under the Background of Supply-side Reform
}

\author{
Kun Zhang \\ Xi’an Peihua University, Xi’an Shaanxi, 710125
}

Keywords: supply side reform; news products; innovation research; media technology

\begin{abstract}
In the era of big data, data news has become an innovative element in television news. When data news is in the ascendant, it is necessary to rationally classify the innovative path of TV media application data, so as to effectively enhance the efficiency of TV news program innovation. Based on the background of supply side reform, this paper describes the data application form of TV news and the structural change of data to TV news, hoping to promote the direction of innovations of data news program. At present, there are endless forms of data journalism in China. For TV media, how to combine supply side reform with perceptual visualization media is an important issue. This paper argues that the truly pioneering innovation should be based on respecting for the rule of TV transmission, and dig deeper into data logic, combined with the strengths of the two, and focus on integration and innovation.
\end{abstract}

\section{Introduction}

In November 10, 2015, general secretary Xi Jinping put forward the concept of supply side structural reform in order to enhance the power of economic development at the central finance and economics leading group meeting. In recent years, China has entered an important period of deepening the reform. News product innovation has also had a profound impact [1-2]. Influenced by western social thoughts and multiculturalism, the news product values have changed slightly. To achieve balanced development between supply side and demand side, we should scientifically apply the way of thinking of supply side reform, innovative ideas and teaching methods, and comprehensively promote the innovation of news products [3]. With the continuous development of Electronic Science and technology, people rely more and more on the network in the fields of learning and work. Many people begin to use new media for news dissemination, and then transmit public opinion and news events to more people. Compared with traditional communication mode, this mode is more convenient and faster [4-5]. With the continuous development of the new media era, the communication mode of news will surely go on the path of innovation, and then the news content is more universal and popular.

\section{The essence of the supply side reform}

\subsection{The meaning and essential requirements of the supply side reform}

The supply side reform is a new concept proposed by the Chinese native, but the supply management advocated by the Western supply school is not a new concept. Although the supply side reform has its own local elements, it cannot be divorced from the view of the supply school from the point of view of its origin. Therefore, in order to fully understanding the basic connotation of supply side reforms, the need to start from the beginning of supply management theory, and clarify the association between demand management, the difference between the clear and China's supply side reform, and then discusses the specific connotation of supply side reform in the context of Chinese.

The essential requirement of the supply side reform is to improve the quality of supply, optimize the structure of the system and provide better products to meet the needs of the masses [6]. This requires not only the quantity of the products to be produced enough, but also the variety of the 
products, and the quality of the products must be high quality. Thus, the structure of scientific rationalization will be formed, providing effective and practical supply, making the production and consumption reach a consistent and seamless docking. That is to say, we need to remove some irrational old structures through the supply side reform, and form a complete and sound structure and establish a new scientific mechanism. Our production should be based on the actual needs of consumers, proceed from the actual market situation, follow the principle of seeking truth from facts, and adjust in time according to market changes and needs, so as to maximize the supply efficiency. In the field of agricultural production, it means to develop green agriculture and promote the modernization of agricultural production [7]. To realize the agricultural supply side reform is to unswervingly take the green agricultural road and vigorously develop a modern and healthy ecological green agriculture.

\subsection{The relationship between supply management and demand management}

The supply management is relative to the demand management and both are the important means of macroeconomic regulation. The logic of core management of demand management can be briefly summarized as follows: government intervention -- using monetary policy and fiscal policy to increase stimulus and increase demand economy growth. That is to say, demand management emphasizes the government's adjustment of the total amount of the market, and uses monetary policy and fiscal policy to stimulate economic development, increase market demand and further promote economic growth. The logical route of supply management is as follows: reduce government intervention - use tax reduction policy - enhance stimulation - increase supply economic growth. The difference between them is mainly reflected in timeliness, pertinence and application stage. See Table 1 for details.

Table 1. Supply management and demand management

\begin{tabular}{|c|c|c|}
\hline Difference & Supply management & Demand management \\
\hline Timeliness & Long-term & Short-term \\
\hline Pertinence & $\begin{array}{c}\text { Adjustment of economic } \\
\text { structure }\end{array}$ & $\begin{array}{c}\text { Adjustment of economic } \\
\text { aggregate }\end{array}$ \\
\hline Policy means & $\begin{array}{c}\text { Administrative } \\
\text { management }\end{array}$ & Fiscal policy \\
\hline Application stage & Developing country & Developed country \\
\hline
\end{tabular}

Chinese scholars systematically expounded the development path of demand management and supply management in the history of economic development, and put forward two negation of supply side economics school. The evolution from say's law to the Keynes doctrine, the Keynes doctrine to supply school, this is the first stage. The second stage is from the supply school to the restoration of Keynes's doctrine, and then from the Keynes doctrine to the supply management [8]. The development background of the negation of the negation to probe into the two, we find that the concept is not a contradiction between the appearances of another wave of the supply management and demand management, but the context in different times, in different levels of economic development in the two different. In addition, a deep reason that can not be ignored is that the choice of supply management and demand management is closely related to the degree of market development [9]. Compared with those with a high degree of marketization, those developing countries with low marketization need more emphasis on supply management.

\section{The essential features and functions of the TV media data news}

The data provide material for TV news, which is different from the traditional mode of production. The record of the data to the objective world does not exist in the value orientation, and the subjective judgment is not mixed. The news is based on the production data well, especially in the era of big data and data level more, covering a wider range [10]. Having large data is equivalent 
to doing a large scale research, so there are more problems that can be explained. The data news brings the TV news to a more objective and rational position.

The innovation of data news is not only to simply visualize the boring data, so that people can read the data more intuitively. The reason why it is called news is to find hidden values through the analysis of the data. This kind of derivation based on mass objective data is missing from traditional TV. The data have given the television media a more profound insight. Of course, it also requires that the news should not only have the ability to obtain information in the past, but also to develop super data analysis ability.

Small data era production mode decided that traditional TV news can only choose to depict local news events, to reflect the panorama of events. If news events and news parties are equivalent to pixels, they can be spliced into an understandable but inaccurate news picture. From the perspective of information presentation, traditional TV news is a relatively vague simulation medium. Because of the large number of samples, the accuracy of the data news is much higher than that of the traditional news [11]. Of course, data news will be subject to an objective nature, because interpretation and data selection are still possible to be manipulated artificially. But this is the subjective choice of the user, and the data news from the production process does improve the accuracy of the traditional news. The innovation pattern of the news media is shown in Figure 1.

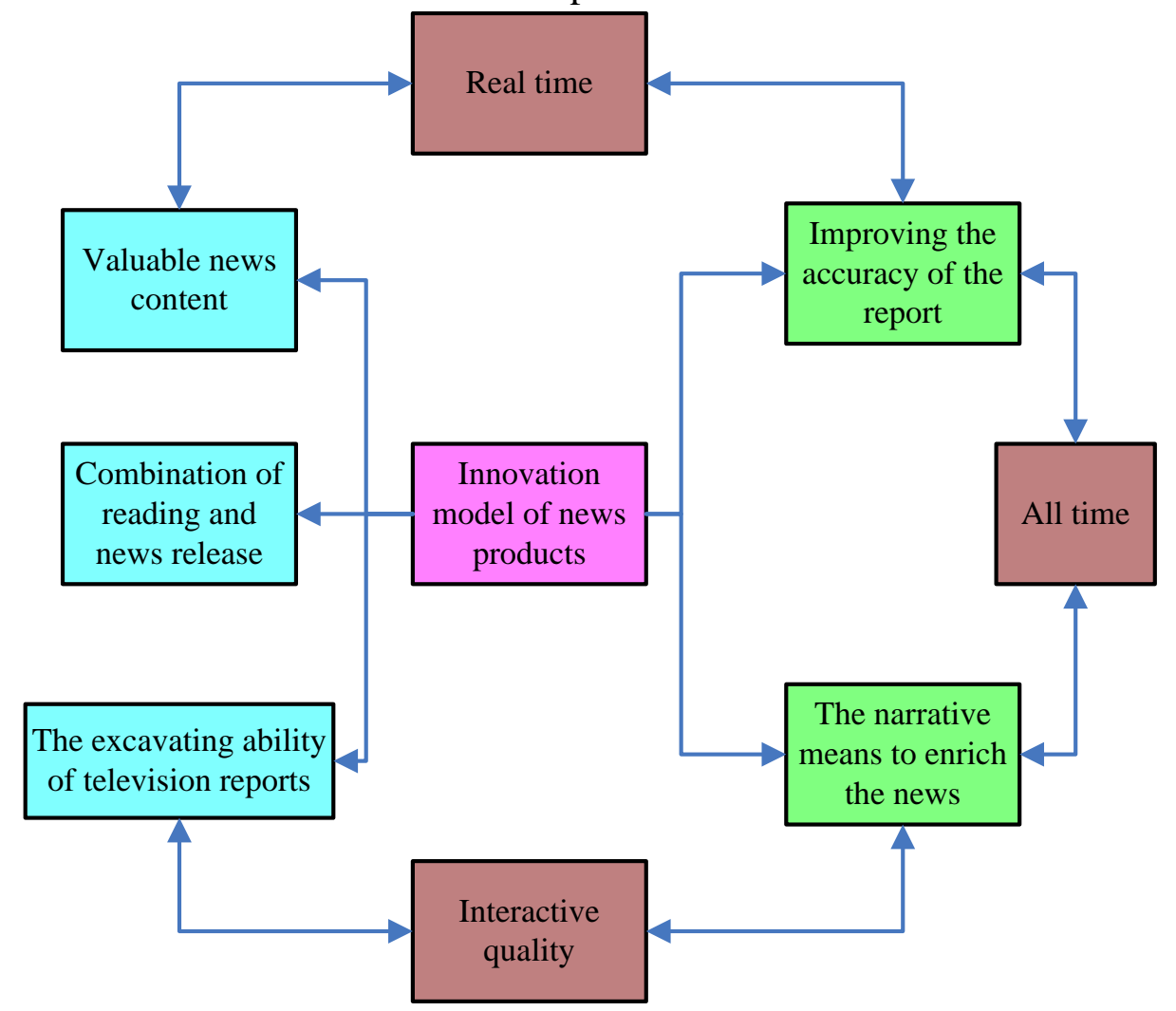

Figure 1. The innovation model of the news media

The television data news should change the source of the news, which is rich in visual form, and the end point is "news story". This shows that the most important function of data news is to help the editor get rid of the dependence on the scene and empty shots, simplify the complex data by means of numbers and icons, colour blocks and dynamic diagrams, and tell the story information in a variety of ways.

\section{Thinking on the innovation direction and optimization path of data news}

It is an important work direction for innovation in the era of big data to innovate the mode of production and enrich the narrative voice of the television media. Using the above data features to optimize the existing program frontiers, we have the following directions. But we need to point out that data news is one of the forms of TV news. The broadcasting platform and the audience 
constitute no significant changes in the form of innovation, so the author thinks that the data news still needs to conform to the narrative law of television [12]. "Data itself is not meaningful. Only by putting data in a specific context and exploring the relationship between data and data from the perspective of human impact, can we interpret data and give meaning to achieve the effect of communication.

\subsection{Exploring more ways to combine network information: expanding data and data types}

In the future data and news production, the industry can think outward to expand and combine more new media platforms. At the same time, think about how to include more data types and dig deeper data value. Such as geographic location, hierarchical data, high level data, time data, text visualization, cross media visualization and keywords cloud can be the source of TV data. In addition, there are both resources and two development and utilization. In the samples collected, the ratings of $48 \%$ of the TV programs will significantly affect the statistical results of the related tweet release. On the other hand, the total volume of tweet's release has a significant impact on the ratings of 29\% TV programs [13]. It can be seen that non - structural data (review resources) can not only make the list of topics and word clouds, but also become the focus of attention in the future. In addition, the output form of the data can also be diversified.

\subsection{Make great efforts to make a breakthrough in the form of visual expression}

The narrow understanding of the data news refers to the conversion of the logical thinking of the digital to the image thinking through the technology of data visualization. This view ignores that the kernel of the data news is cold and harsh, but the extension can be the art of information. "In the human cerebral cortex, $40 \%$ is the visual reaction zone, and the human nervous system is naturally most sensitive to the image information." So we can't limit data news to combing messy data with words, numbers, symbols, or simplifying information relationships [14]. On this basis, we need to pay attention to the presentation of information at the same time, so that it has a new sense of form, powerful infectious force and good information transmission effect. For example, the European aviation route map made by NATS, in the context of the whole European continent, simplifies each flight to a blue light point. With the passage of time, Europe's major aviation lines or parallel expansion, or a little gathering, has formed a rich and aesthetic work.

\subsection{User value-added news: open the information source, promote the two transmission}

The popularity of smartphones and tablets makes the media's participation speed up. Data news is born in the large data media environment that the user promotes, and its fundamental growth impetus comes from the user. The development of data news needs to attach importance to the user experience and to attach importance to the interaction with the users. The guardian chose to open the massive data, text and video data to the audiences in a total of more than 1 million stories, and sent the invitation to the users to participate in the rearrangement of the information. Of course, compared to traditional news, the participation of data news is only small crowd behaviour. However, with the continuous reduction of the technical threshold, the users of the data news will also increase gradually. At the present stage, the feasible direction of thinking is how to make information visualization and unique news value and friendly participation of the interface, so that users can participate in the establishment and sharing of data actively.

\section{Conclusions}

On the background of the supply side reform, this paper studies the innovation methods of news products. Because of the limited energy and time, this article only puts forward some views from the macro point of view, and does not study in depth from the micro point of view. In the future research work, we should focus the work on the micro point of view. Change the way readers read news dissemination model of innovation under the new media era is imperceptibly, only in the new media era the news dissemination pattern innovate and explore the profound meaning, they can better interpret the news, and a more comprehensive grasp of the characteristics of news 
dissemination mode innovation under the new media era, in order to reflect the news dissemination the authenticity and rapidity.

\section{References}

[1] Geng C H. Research on Rural Financial Product Innovation Based on the Structural Reform of Agricultural Supply Side[J]. Journal of Changchun Finance College, 2017.

[2] Wen-Jie D U, Zhang H. Research on New Innovation Mechanism of China Pilot Free Trade Zone based on Supply-side Reform[J]. Copper Engineering, 2016.

[3] Bai P F, Wang B Y. A Research on the Innovation and Development of the Rural Finance Under the Reform of the Supply-side[J]. Journal of Yanan University, 2016.

[4] Wei F, Feng B M, Wang J, et al. Research on Green Innovation of Traditional Manufacturing Enterprises in the Context of Supply Side Structural Reform[J]. 2017(icem).

[5] Ren-Yan L U. Research on the Library Service Innovation under the Guidance of Supply-side Reforms[J]. Journal of Library \& Information Sciences in Agriculture, 2016.

[6] Xia J Z. Innovation Research on Entrepreneurship Education in Universities under the Background of the Supply-side Structural Reform[J]. Journal of Shandong Youth University of Political Science, 2016.

[7] Xiao W S, Zhou R R, University S. The Research of Linkage Mechanism about Supply Side Reform and Innovation Driven Strategy: Based on China's Economic Growth Momentum Transformation[J]. Value Engineering, 2017.

[8] Yang S X. Research on Business Management Innovation in the Context of Supply-side Structural Reform[J]. Science Technology \& Industry, 2017.

[9] Wang S Y. Research on Innovation and Practice of Higher Vocational Supply Side Talent Training Quality Reform[J]. Journal of Liaoning Higher Vocational, 2017.

[10] He X J, Shen J L. Research on technical innovation efficiency in Chinese medicine manufacturing under structural reform of supply-side[J]. Chinese Traditional \& Herbal Drugs, 2017, 48(1):219-224.

[11] Sheng C X, Huang H Q. Research on Constructing Innovation System to Support the Supply Side Structural Reform[J]. China Soft Science, 2017.

[12] Huang J, Economics S O. Research on Supply side Reform Under Innovation Driven[J]. Journal of Hebei University of Economics \& Business, 2016.

[13] Wei X M, Pan A L, Management S O, et al. Technology Capital Optimal Configuration and Countermeasure Innovation Under the Background of Supply Side Structural Reform[J]. On Economic Problems, 2017.

[14] Zhan J, Wang Z J, University S M. Innovation Capability and Performance of High-end Service Firms under the Background of Supply-side Structural Reform: Empirical Research Findings from the Synthesis Perspective[J]. Business Management Journal, 2017. 